\title{
OBSERVATIONS ON THE LILLE EXPERIMENTS ON THE COMPARATIVE EFFICIENCY OF ROPES AND BELTS FOR THE TRANSMISSION OF POWER.
}

\section{By Profissor DAVID S. CAPPER, of London.}

Experiments on the Efficiency of Ropes and Belts for the Transmission of Power have been few; and for the most part such knowledge as is at present possessed on this subject has been indirectly derived. The investigation is perhaps as important as any in its influence upon industrial economy; but the problems involved are complex, and experiments in order to be conclusive must be on such a scale as necessarily to involve a large expenditure both of time and of money. This has hitherto paralyzed effort; and the Société Industrielle du Nord de la France are to be congratulated upon the enterprise and liberality of certain of their members, whereby experiments on a large scale have been rendered possible. All the arrangements were carried out and all the expense was borne by French engineers; but with a courtesy worthy of general imitation the Société invited the Institution of Mechanical Engineers to send a member to represent them at the trials. At the request of the Council the author attended in that capacity the preliminary meeting held in November 1893; and being then elected one of six additional members of the Commission, was present at the subsequent meetings and at the trials.

The programme, drawn up by the President of the Conmission and submitted to an early meeting, confined the scope of the trials to a direct comparison between the gross power required to overcome a fixed resistance through ropes and through belts. With a view to obtaining an absolute determination of the power absorbed in the gearing, the author suggested that the fly-wheel should be designed so that brake tests could be carried out, and that a series of such 
trials should be undertaken. But after consideration of this proposal, it was decided by those who were responsible for carrying out the experiments to adhere to the original limits. A further suggestion by M. Neu-that the engine might be eliminated altogether by employing three dynamos, the second of which could be driven from the first, and, running as a motor, could drive the third through the rope and belt gearing-was found impracticable, owing to the extent and cost of the installation which it would involve. Thus limited, the experiments were arranged and carried out admirably, and with all possible precautions.

The engine is of the horizontal two-crank compound type, and was constructed by Messrs. Dujardin and Co. to drive their workshops. It was specially fitted with twin fly-wheels for the trials. The cut-off is effected by vacuum plungers, controlled through a trip gear by the governor. An injection condenser maintained a constant vacuum, the back pressure in the low-pressure cylinder being less than 3 lbs. per square inch. The air and feed pumps are worked off the high-pressure cross-head.

Indicators.-Four Tabor indicators were used, and previously to the trials their springs were calibrated under steam by M. Bonet against two standard gauges. The corrected scales are given in Table 2, page 609, and these have been employed in all cases for calculating the horse-powers. For all the trials the position of the indicators remained unaltered; and as each end of each cylinder was indicated by the same observer throughout, the observations could be strictly compared with one another. The indicator pistons were well oiled every ten minutes; and all fonr diagrams were taken simultaneously at the instant when the signal was given that the resistance was steady at the required value. Every care was taken to prevent inaccuracies due to unequal pressure of the pencil; and the diagrams were remarkably uniform, and free from any indications of such defects. The author took a number of diagrams in which pencil contact was maintained for half a minute; and the outline showed a scarcely perceptible thickening, the greatest fluctuations taking place, as would be expected, in the high-pressure cylinder. 
Boiler.-The boiler was of the locomotive type, fitted with steel tubes having internal feathers for increasing the heating surface. The stoking was excellent, and the boiler pressure was remarkably steady from beginning to end of the trials.

Dynamo.-The dynamo was of the four-pole type, the armature being Gramme-wound with 252 turns of rectangular copper, forming three sections. The armature resistance was $0.001585 \mathrm{ohm}$. The field magnets were shunt-wound, the resistance of the field winding being $4 \cdot 642 \mathrm{ohms}$; and the air space between the core and the polepieces was 0.787 inch. The efficiency of the whole system, E.H.P. $\div$ I.H.P., was rather over $68 \frac{1}{2}$ per cent., measured on the volt and ampère meters. The rated output of the dynamo was 1,200 ampères at 113 volts, or $135 \cdot 6$ kilowatts, when running at a speed of 265 revolutions per minute.

Fly-wheel and Pulley.-The breadth of the fly-wheel and pulley for the ropes was 13.08 inches, and for the belts 18.48 inches, as shown in Figs. 1 to 5, Plate 151.

Results of the Trials.-In the summary table, page 620, will be found the means of the fifteen observations taken during each trial. The maximum mean, 160.23 horse-power, was developed in the triel of the Domange leather belt, and the minimum mean 158.54 in the second trial of the ropes. The difference is 1.05 per cent. of the maximum mean. From the method adopted in the experiments, this represents the whole difference found between the efficiency of the two plans. On referring to the table of details however, it will be seen that during each experiment $a$ greater variation of power was observed than this mean. In one trial the difference between individual readings reached $5 \cdot 7$ per cent., while the least variation in any trial was $3 \cdot 1$ per cent. As each observation is complete in itself, and as the resistance was constant to 0.4 per cent. throughout the trials, and every possible precaution was taken to ensure uniformity of conditions, it is evident that a constancy to within about 3 or 4 per cent. is the utmost which can be relied upon. The indicators being carefully calibrated, and used only for comparison, would give results true within these limits; but the unknown 
mechanical efficiency of both engine and dynamo, the errors of observation, and the possible changes in the actual amount of the power absorbed in the gearing, must elearly have affected the consecutive readings to an amount sufficient to produce the larger variations. It appears therefore that the difference between the efficiencies of the rope and the belt gearing used in the trials was inappreciable within these limits; and to have practically demonstrated this fact is a result of sufficient value, although the more important question, of the actual power absorbed by the gearing, is no nearer solution.

Slip.-In measuring the slip of the belts the effective radius has been taken from the centre of the shaft to the surface of the fly-wheel and pulley rims. The thickness of the belt has thus been neglected. If the belt thickness be added to the diameter of the fly-wheel and pulley, the slip would be more correctly stated as follows:-

TABLE 14.-Slip of Belt.

\begin{tabular}{|c|c|c|c|}
\hline Description of Belt & $\begin{array}{l}\text { Cotton. } \\
\text { Lechat. }\end{array}$ & $\begin{array}{l}\text { Leather. } \\
\text { Lemaire. }\end{array}$ & $\begin{array}{l}\text { Leather. } \\
\text { Domange. }\end{array}$ \\
\hline 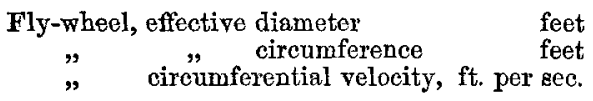 & $\begin{array}{l}16 \cdot 413 \\
51 \cdot 563 \\
67 \cdot 934\end{array}$ & $\begin{array}{l}16 \cdot 423 \\
51 \cdot 594 \\
68 \cdot 001\end{array}$ & $\begin{array}{l}16 \cdot 418 \\
51 \cdot 579 \\
68 \cdot 109\end{array}$ \\
\hline $\begin{array}{cr}\text { Pulley, effective diameter } & \text { feet } \\
, " \quad \text { circumference } & \text { feet } \\
" \quad \text { circumferential velocity, } & \text { feet per sec. }\end{array}$ & $\begin{array}{r}4 \cdot 953 \\
15 \cdot 560 \\
67 \cdot 708\end{array}$ & $\begin{array}{r}4 \cdot 963 \\
15 \cdot 592 \\
67 \cdot 751\end{array}$ & $\begin{array}{r}4 \cdot 958 \\
15 \cdot 576 \\
67 \cdot 945\end{array}$ \\
\hline $\begin{array}{l}\text { Slip of Belt, actual } \\
\quad " \quad \text { percentage }\end{array}$ & $\begin{array}{l}0.226 \\
0.333\end{array}$ & $\begin{array}{l}0.250 \\
0.368\end{array}$ & $\begin{array}{l}0 \cdot 164 \\
0 \cdot 241\end{array}$ \\
\hline
\end{tabular}

The speed of slip reckoned as above for the belts is from about 10 to 15 feet per minute.

With regard to the ropes, it is uncertain to what depth they sink into the grooves when running under load. In Table 13 the slip of the ropes has been caleulated on the assumption that the effective radius is the distance between the centre of [the shaft and the centre 
of the rope when at rest. But on removing the ropes the author found that the polished ring showing where rubbing had taken place was 5-8ths inch broad, and lay within that radius, as shown in Fig. 3, Plate 151. It seems probable therefore that the true effective radius lies within the limits assigned to it; and as a small decrease in the effective circumference would considerably increase the slip, it seems donbtful, in the absence of special experiments, what is the real slip of the ropes.

Previous Experiments. Morin.-The earliest belt experiments on record were made by General Morin, who in 1834 investigated the laws governing the friction of leather belts on wooden drums of three different diameters, and on cast-iron pulleys. From each end of a black curried leather belt, suspended over a fixed drum, were hung weights, which at one end were gradually increased until slipping commenced. The belt had been made pliable by previous use; and Morin estimated that the loss due to stiffness might be neglected in comparison with the friction of slipping. With woights of which the mean varied between 41 and 125 lbs. per inch of width, and with arcs of contact varying within a range of proportion of 1 to 8 , the coefficient of friction remained sensibly constant. In another series of trials, dynamometers were inserted on both sides of an endless vertical belt, which passed round a pulley and an oak drum. Weights were hung in a scale-pan attached to the circumference of the drum, which with the pulley was allowed to rotate as far as the dynamometers would permit. It was thus possible to measure the tensions on the two sides of the belt, under the three conditions of rest and motion and when about to slip. The normal tension could be increased by tightening the ends of the belt when at rest. Loads increasing from 0 to $175 \mathrm{lbs}$. per inch of width caused no appreciable variation in the sum of the two tensions until slipping began. The greatest single tension applied was $174 \mathrm{lbs}$, the least 11 lbs., and the sum reached a maximum of $206 \mathrm{lbs}$. The coefficient of friction varied between 0.544 and 0.596 , the mean being 0.573 .

Briggs and Towne.-In the journal of the Franklin Institute for 1868 a paper was published giving an account of experiments made 
by Messrs. Briggs and Towne upon the coefficient of friction between leather belts and cast-iron pulleys, and upon the strength of belts. Pulleys 12 inches and $23 \frac{5}{8}$ and 41 inches in diameter were employed, all of them having been in workshop use for some years previously. The belts were in various conditions: some were new; others had been in use some time and were in good running order; and others, although not completely worn out, were weakened by wear. The arrangements were similar to those of Morin's first experiments, scale-pans being attached to both ends of the belt suspended freely over a stationary pulley; in one scale-pan the weight was constant, and in the other weights were gradually added until the belt slipped freely; the load was then recorded. For all the experiments the velocity of slipping was about 200 feet per minute, and care was taken that the weight should be only just sufficient to cause free sliding without acceleration. The arc of contact was $180^{\circ}$ for all the experiments. With tensions of 7 to 110 lbs. per inch of width, the mean of 168 experiments gave a calculated coefficient of $0 \cdot 58$, thus confirming Moriu's results. As it was found impracticable to imitate exactly the working conditions where free slipping should not take place, Mr. Towne considers that a coefficient calculated on the assumption that the working tensions are 60 per cent. of those applied in his experiments, or 0.42 , will better represent the working value. In arriving at this result, no account was taken of the velocity of the belt, which was inappreciable, or of the dimensions of the pulley. The ultimate strength of leather belts of 7-32nds or 0.219 inch thickness Mr. Towne found to be about $200 \mathrm{lbs}$. per inch of width, when the rupture was through the laced joints; when through the rivet holes of the splices, a strength more than half as large again was obtained; and when through the solid leather, it reached 675 lbs. per inch of width.

Leloutre.-In 1878 an extensive series of experiments was made by M. Leloutre upon the elongation and breaking strain of leather driving belts, and the slipping of belts and cords. By attaching weights to narrow thongs cut from different belts, he found that the maximum resistance to stretching of ordinary leather is at a load of 850 lbs. per square inch. At this load the most economical results 
will be attained. The slip he determined in the same manner as Morin, by hanging belts with both ends free over a stationary polished pulley. By carefully manipulating the weights at the two ends he obtained constant speeds of slip down to as slow as 3-8ths inch per minute. The diameter of the pulleys varied from 4 inches to 8 feet, and the width of belt from 3-8ths inch to 12 inches. The arc of contact was from $180^{\circ}$ to $1,260^{\circ}$. The ropes were $1 \frac{1}{4}$ inch diameter, and were tried both with plain pulleys and with circular and V-shaped grooves. The coefficient thus found for now leather belts was $0 \cdot 155$, for old greasy belts 0.20 to 0.22 ; for the same belts on unpolished pulleys it rose to $0 \cdot 33$. With moist leather the coefficient was sometimes as low as $0 \cdot 12$. With ropes and smaller cords its value was about 0.070 to 0.075 . In replacing with belting some large spur wheels, through which 750 I.H.P. was passed, M. Leloutre had the opportunity of making careful trials both before and after the change. The total loss of power in engine and gearing with the spur wheels was 208 H.P., and with the belts 184 H.P. Reckoned on the grofss power, the belts were therefore about 3 per cent. more efficient than the wheels. As it has been shown by careful experiments made by Mr. Wilfred Lewis that the average efficiency of well-cut spur gearing is about 93 per cent., M. Leloutre's experiment would indicate an efficiency of about 95 to 96 per cent. for the belting.

Lewis.-In 1886 experiments were carried out by Mr. Wilfred Lewis for Messrs. Sellers and $C_{0}$, to determine the slip and efficiency of belt gearing. A large number of observations with different kinds of belts showed that with belting properly arranged the slip should not exceed $1 \frac{1}{2}$ to 2 per cent. If however slipping occurs to any considerable extent, a black oily deposit accumulates, and the coefficient being reduced the slip is largely increased. By measuring the torsional moment required to run a straight belt at different speeds, the total efficiency of the gearing was calculated to be 97 per cent. of the gross load, thus practically confirming M. Leloutre's direct experiment. Contrary to the theory of Poncelet and the experiments of Morin and Briggs, Mr. Lewis found that the sum of the tensions does not remain constant, but increases 
with the load as much as 33 per cent. with vertical belts. As the efficiency and the slip were the same, whether thick or thin belts were employed, Mr. Lewis could detect no loss from stiffness. He therefore concludes that economy depends chiefly upon slip and journal friction.

Lanza.-Professor Lanza, also in 1886, supplemented the information obtained by previous experimenters upon slip, by seeking to determine:-first, what is the average speed of slip under ordinary practical conditions of working; second, what is the coefficient of friction obtained with the average speed of slip; third, what is the variation of the coefficient with different kinds of pulleys and belts. By careful experiment he finds that the average speed of slip under ordinary working conditions is from 3 to 12 feet per minute; and at that speed the coefficient of friction has a mean value of 0.27 .

Fauquier.-Further information has been gained by a series of trials made by M. Fauquier, the results of which are recorded in the Proceedings of the Société des Ingénieurs Civils, 1893, page 558. With a smooth-rimmed pulley running on carefully prepared bearings he determined the weight required to maintain a constant speed of rotation, when attached alternately to loaded belts and loaded ropes passing round the rim. The added effect of the grooves of a rope pulley was determined by measuring the moment of resistance due to the sticking of the rope in the groove. Pulleys of three different diameters were tried. From his results he derives a formula by which the loss of power due to the stiffness of the ropes and belts may be calculated; and concludes that rope gearing absorbs from one and a half to three times the total power that is lost in belt gearing. This he attributes chiefly to stiffness; but it must be remembered that the measurements upon which he relies are of necessity liable to large proportionate errors. His results must therefore be received with caution in the light of the Lille results.

Pearce.-Messrs. Pearce Brothers of Dundee also made a number of experiments in 1884 to determine the coefficient of friction between ropes and grooved pulleys. With ungreased pulleys the coefficient varied between 0.57 and 0.88 ; with greased pulleys between 0.38 and $0 \cdot 41$. 
Conclusion.-In almost all these experiments the chief object has been to determine the limit of load under ordinary working conditions, beyond which a belt will slip upon its pulley. The work of Morin left out of account the effect of speed of slip upon the frictional coefficient; and although Messrs. Briggs and Towne recognised its influence, they were unable to carry out experiments of a satisfactory kind at the speeds of slip due to the elasticity of belts under ordinary working conditions. Other experimenters, working at lower speeds of slip, obtained conflicting results; and it was not until 1882, when Professor Holman experimented at varying speeds of slip with the express object of finding the cause of the discrepancies, that the coefficient was known to vary from 0.58 , the value obtained by Morin and Mr. Towne, down to $0 \cdot 12$ when the speed of slip was sufficiently reduced. Since then Professor Lanza has set all doubt at rest by a careful and elaborate series of tests, in which the average speed of slip under ordinary conditions has been determined, and the value of the coefficient of friction for that speed found to be 0.27 , a value which $\mathrm{Mr}$. Towne accepts as more accurate than that which he was forced to deduce without direet confirmation. It is therefore possible to ensure that no excessive loss shall occur from slip. But there still remain residual lossesslip due to elasticity, work in overcoming the stiffness of belts, reduction of the coefficient at high speeds by centrifugal action and by air-about which very little is definitely known.

The experiments of Mr. Lewis and M. Leloutre tend to show that the total loss in well-designed belt gearing does not exceed 3 or 4 per cent. of the gross power transmitted; and M. Fauquier has investigated the losses due to stiffness, with results which require confirmation before they can be deemed conclusive, and with which the observations of Mr. Lewis directly conflict.

By the Lille trials it has been shown that ropes are practically as efficient as belts, at any rate at the speeds and powers there tried; though some doubt has been cast upon the actual value as previously determined of the losses in belt gearing, from the fact that the variation which was found between individual observations at Lille exceeded 3 per cent. It is to be regretted that it was not found 
possible with such a unique installation to extend the limits of the research; but it must be admitted that the difficulties were great, and the increase in the outlay would probably have been large.

In conclusion the author desires to express his thanks to M. Dubreuil, M. Dujardin, and the members of the Commission and of the experimental staff, for the kindness which was shown him on all occasions, and for the ungrudging manner in which facilities were afforded him for acquiring information upon all that concerned the trials.

\section{Discussion.}

Professor CAPPER drew attention to the specimens which had been sent in illustration of the Report: pieces of belting from M. Domange, M. Lechat, and Messrs. Lemaire and Son; and rope from Messrs. Saint Brothers. He did not wish it to be imagined that the brief summary he had given of previous experiments (pages 625-8) was in any way an exhanstive review of all the experiments which had been made. He had selected those experiments which seemed to him to bear most directly on the efficiency of rope and belt driving; and if by this means any information could be elicited as to additional experiments, the value of the discussion would be greatly enhanced.

Mr. Jamas Pratr, Member of Council, was sure the Members must all feel much obliged to their French neighbours for the enterprising manner in which they had carried out these experiments ; and to Professor Capper for the great pains he had taken in summarising the results. It was a great pity however that the experiments could not have been further extended, and the rope and belt gearing tested at different speeds. Some fow years ago he went 
northwards to see some rope driving in Lancashire, where the speed of the ropes was something like 6,000 feet per minute, whereas in the Lille experiments it was only 4,000 feet per minute; and the engineers who were introducing the higher speed found that, as the speed of the ropes increased, the steadier was the driving and the better were the results. The centrifugal force seemed to take away a great deal of the friction from the grooves in the pulleys, and the ropes ran as steady as a line; there was no vibration or undulation at all in the sag. At that time he was told they intended going up to 7,000 feet per minute; but he had not followed their progress since, and he did not know what the result of time had been in their experience. So far however it went to show that, the higher the velocity, the greater was the advantage of rope driving. All engineers knew the trouble there was with belt gearing from the laps of the joints ; and he had himself had the same experience as others in this respect. When called in to advise as to irregularity of engines and driving gear, he had often found it was due to the belt driving the governor. In these days of course no good engine was made with a belt-driven governor; but formerly it was so, and there was consequently an up and down motion of the governor every time the belt joint went over the driving pulley or the driven pulley. Besides this, there was also the difficulty with belts of getting a joint which would not affect the safety of the belt itself, as well as of the shafting, in passing over the two pulleys. Ropes of course had not that disadvantage; and as far as his experience went, rope gearing was the best for high speeds. Probably some of the Lancashire members would be able to give some information about rope driving at the high velocities he had mentioned, which were higher than any cast-iron wheel would stand. Cast-iron rope-wheels were used as far as safety would permit; and beyond their limit the diameter was increased by the use of wheels made with wroughtsteel arms and rims, carefully turned and balanced; the result was then most excellent driving.

Mr. Miohate Longridge confessed to feeling a certain amount of disappointment after reading the Report; the elegance and 
(Mr. Michael Longridge.)

completeness associated in his mind with the work of French engineers had led him to hope for more information than the Report contained. Presumably M. Dubreuil and his colleagues had carried out the experiments as completely as circumstances permitted; but he could not help thinking that they had gone the wrong way about them. The experiments appeared to have been conducted on what were called practical lines, that is, under ordinary working conditions. Experiments conducted under such conditions were to his mind valuable for proving a particular fact or statement or the fulfilment of a guarantee; but for experimental purposes he was afraid they were generally unfruitful. The conditions which obtained in ordinary practical working were generally not those which were required for purposes of investigation. Where experiments were made under practical conditions it was necessary to have apparatus of large size, such as was used for industrial purposes. It was necessary therefore to have apparatus which was costly, which it was difficult to alter, and which must more or less be worked under the conditions of ordinary practical working. The result of experiments made with such an apparatus was consequently more or less an isolated fact. It exhibited the final resultant of a number of forces, some reinforcing, others teuding to neutralise the rest. If any of these forces were to be altered or varied, it would be impossible from the result of the experiment to foresee what the effect of the alteration or variation would be. In fact, the result of an experiment made under what were called practical working conditions, if expressed graphically in the form of a diagram, consisted generally of a single solitary point upon the paper. It was unconnected with anything else, and there was no means of telling in what direction it would move on the diagram, if the conditions were varied under which it was obtained. The experiments at Lille seemed fairly to illustrate this view. In the first place they had evidently been costly; in the second place the cost had evidently militated against variation of the conditions under which. they were made; and in the third place they had yielded only a single isolated fact. So far as it went, that fact was valuable of course; but such isolated facts were often used to draw 
unwarrantable conclusions. For instance, the conclusion on page 607 he thought was not quite such as could be agreed to unconditionally. It was that, "in the transmission of power, ropes and belts when well arranged absorb almost the same amount of power." No doubt it was qualified by the words "well arranged"; but what did this qualification mean? It seemed to him that it must mean, under the conditions under which these particular experiments were made. Even then however he thought the conclusion could hardly be drawn that under those same conditions ropes and belts would in general absorb almost the same amount of power. Suppose, for instance, that instead of transmitting 160 H.P. it were required to transmit 1,600 H.P., keeping the tensions of the ropes the samewhich by the bye were not known-and also keeping the speeds the same; what size of wheels and pulleys would be needed? The belt of $177 \frac{1}{2}$ inches width would need a drum nearly 15 feet wide, and the ropes a drum 10 feet wide. The weight of the 15 -feet belt drum would considerably exceed the weight of the 10-feet rope drum. Consequently the pressure on the journals with the belt driving would considerably exceed that with the rope driving; and the friction resulting from the pressure on the journals was well known to be a most serious matter indeed. It seemed to him therefore that, by merely increasing the power transmitted, the conclusions arrived at from these experiments were at once upset, although all the other conditions were kept the same. Going further, and supposing the ropes were loaded as they were in Lancashire, namely to 50 per cent. above their load in these experiments, there would then be a belt drum 15 feet wide against a 7-feet rope drum; and the difference in the engine friction between those two drums would amount, he believed, to nearly 30 H.P. Therefore he thought the conclusion that the power absorbed would in general be the same was hardly warranted. Indeed it seemed to him rather curious that the power absorbed should have come out so nearly the same in the two sets of experiments, considering the differences in the frictional resistances overcome. Taking the coefficient of belt friction given in paget 628-9 of the paper, namely 27 per cent., he calculated that the tension on the belts must have been about double the tension on 
(Mr. Michael Longridge.)

the ropes. Consequently the journal friction due to the tension must have been considerably greater with the belts than with the ropes. Then there was no doubt some difference in the resistance of the belts and ropes to bending, though he thought it would not be great. Also there was a resistance which the ropes opposed to coming out of the grooves, but no corresponding resistance in the case of belts. Finally there was the resistance of the air. How was it that all these resistances happened to balance so completely in the Lille experiments? The prior probability that they would not do so suggested the question whother they really did. In their absolute amount it must be remembered that all these resistances were small; in page 627 of the paper it was stated that M. Leloutre's experiment indicated that about 5 per cent. of the whole power exerted was absorbed in overcoming the resistance of belting. The variations to be dealt with were therefore variations of a quantity, which was itself only 5 per cent. of the whole power exerted. For measuring these variations it appeared that indicator diagrams had been taken from the steam engine. It seemed to him rather like cracking a walnut and a filbert under a steam hammer, and taking steam diagrams from the hammer to see which required the greater force. In such a case it would have been better to put the two nuts under a lever and hang weights on the end, and so to find that one would take perhaps 16 ounces and the other 18, whereby it would be seen at once what the true difference was; whereas with the steam-hammer diagrams no difference whatever would be found. Something of this sort he feared was what had occurred in these experiments.

So far as the report went, he thought the choice between ropes and belts would have to be determined on other grounds. General experience, as was well known, showed that there was no great difference between the two. But in matters of convenience there was a considerable difference; and he should like to mention one or two advantages resulting from the use of either ropes or belts. Ropes were attended by what was undoubtedly a great practical advantage, namely a much narrower and lighter drum. They also possessed another great advantage in the facility they afforded of driving on the skew, which could not be done with 
a belt without guide pulleys. With ropes two shafts could be driven with great ease when inclined to each other at an angle of about seven degrees; and Mr. Barbour of Belfast, whose firm originated rope driving in this country, had recently informed him, when he was making enquiries on the subject, that even with tolerably large drums there were no serious difficulties in driving two shafts inclined at even fourteen degrees. Then there was the further advantage that the ropes could be put on and taken off one at a time, and thus a faulty rope could be changed without having to stop the machinery. It was said that, if this were done, the difference in diameters of the ropes-the now rope just added, and the old ropes which still continued running-caused a great loss of power. He did not believe that to be the case, and he did not see why it should be so; at all events he did not see why more power should be lost from using conjointly ropes of rather different diameters than was lost by working a belt over a crown pulley. In the latter instance there were the two different diameters- the larger diameter in the middle of the pulley, and the smaller diameter at the two sides; and the difference between these two diameters was greater than the difference in the effective diameter in the grooves of a rope drum with ropes of slightly different size. Then again the ropes ran under a lighter tension, which was certainly a great advantage. Another advantage too in favour of ropes was that they would stand in some positions where leather belts would not stand : for instance, where there was a good deal of heat. On the other hand, he believed ropes were more costly and more troublesome to keep in repair. They required more looking after than belts, and they could not be worked with jockey pulleys as belts could, because the bending in the two opposite directions destroyed them so rapidly.

These were the chief advantages and disadvantages of the two plans; and the conclusion he came to from them was that, for heavy driving and long distances, ropes were undoubtedly preferable; but with light driving, and where the distances were short, belts were equally good, and less trouble to keep in order, though more expensive in first cost. 
The President asked if Mr. Longridge could give his views as to the length of drive for ropes and belts respectively, in relation to the comparative sizes of the driving drum and the driven pulley.

Mr. Longridgin knew an instance of a drum 17 feet diameter driving by ropes a pulley of $9 \frac{1}{2}$ feet diameter, with a distance of only 7 inches between their rims. In another instance a 13-ft. drum was driving by ropes a $7 \frac{1}{2} \mathrm{ft}$.-pulley, and the distance between their rims was only 9 inches. In a third instance, where the ropes had now been on for about eight years, there was a 17 -ft. drum and a $7 \frac{1}{2}-\mathrm{ft}$. pulley, and their centres were 15 feet apart; that would leave $2 \mathrm{ft} .9$ ins. between their rims. These were all short drives for ropes; and there was no difficulty with short drives for ropes, provided enough ropes were put upon the driven pulley. With a given driving drum, the arc of contact on the driven pulley became less as its diameter was diminished, and as the distance apart became less; more ropes were then required. With belts he did not know that there was any limit to the closeness of the drums; by the use of jockey pulleys the drums could be put as close to each other as might be desired.

Mr. Bryan Donkin, Member of Council, believed that rope driving, which Mr. Longridge had montioned as having been originated in Belfast (page 635), had previously been introduced in Alsace in 1852 by Mr. C. F. Hirn of Colmar with ropes of steel wire.* It seemed to him a great pity that the programme of the Lille experiments, which he had received an invitation to attend, had been so limited as the Report showed. The best thanks of engineers were nevertheless due to M. Dujardin for the great trouble and expense he had incurred, and to M. Dubreuil for the opportunity afforded for Professor Capper to be present. It seemed that the practical results for the set of five horizontal ropes, and for the one cotton or the one leather belt working horizontally, were almost the same, as far as the friction was concerned; but this was

* Notice sur la Transmission Télodynamique, par C. F. Hirn; Mulhouse 1867. 
only at the particular speeds and under the particular conditions of the experiment; and he quite agreed with Mr. Longridge that it must not be inferred that the results would be the same under conditions different from those of the experiments and at different speeds. From Table 13 the ropes seemed to have given less than half the slip of the belts ; but from pages 624-5 there appeared to be some doubt on this point. There was the same linear speed in each case, and the same tension per square inch of section. He asked whether the ropes and belts were new at the time of the experiments, and whether they were unusually tight or not. He should also be glad to know the cost of the ropes and belts; and a further question suggested by Mr. Longridge's remarks was the weights of the fly-wheels and pulleys. The interesting summary of previous experiments, given at the end of Professor Capper's paper, he thought would be found highly useful.

Mr. Alfred Saxon agreed with Mr. Longridge in fearing that for practical purposes these experiments were of doubtful value. That the resolution decided upon in page 600 should have been adhered to through thick and thin, was perhaps rather unfortunate. In the first instance an offer seemed to have been received of an engine of 200 H.P., and then the number of ropes seemed to have been decided upon that would transmit the 200 H.P. at a given speed ; and he supposed the width of belt as well. These decisions he presumed had been based on calculations. If so, it would seem that the number of ropes adopted had no doubt been determined on the basis of transmitting about 40 H.P. per rope, so that the five should together be equal to the 200 H.P. which the engine was supposed to develop. But from Table 13 it appeared that, when the experiments came to be carried out, the engine actually developed only about 160 H.P. It would therefore have been an easy matter he thought to take one rope off, when it was found the engine was developing only I60 H.P.; and the four ropes might then have transmitted the 160 H.P. without any more slip than the five did, provided the four had not been working above their calculated power. It was also unfortunate he thought that no other kinds 
(Mr. Alfred Saron.)

of ropes had been tried in addition to manila hemp ropes. In Lancashire he knew of only one large mill, driving about 1,000 I.H.P., which used manila ropes; but that was an exception. The rule in Lancashire certainly was for cotton ropes to be used; and as a cotton belt had been found to test against the leather belts in the Lille experiments, he should have expected that cotton ropes would also have been found to test against the manila ropes. Great caro he thought had been taken in connection with these experiments, so far as they had gone; the results were indeed so uniform, that it seemed to him, as it apparently did to Mr. Longridge also, that they were almost too uniform.

In the comparison of expense between belt driving and rope driving, his experience differed from that of Mr. Longridge in the matter of repairs. An engine with a 28-foot drum and with three belts, each 30 inches wide, had been supplied by his firm to drive about 800 H.P. Those belts had been rather more expensive to maintain than rope driving which had been supplied to other similar works; and his own opinion was that belts of a large size were more expensive than rope driving. Under most circumstances he certainly agreed with Mr. Longridge that rope driving was considerably more favourable than belt driving. For transmitting the same power a rope drum was considerably narrower than a belt drum; in these experiments the rope drum was 13 inches wide and the belt drum $18 \frac{1}{2}$ inches wide (page 623). This was a point which had had to be carefully borne in mind in transmitting large powers; and at the present time most Lancashire engineers would certainly go in for rope driving for large powers, in preference to belt driving, on account of the difficulty of supporting the wider beltdrum without deflection of the crank-shaft in working. During the period that rope and belt driving had been in use, several serious breakdowns had occurred, owing to the length and weakness of the crank-shafts and their consequent deflection; in many instances the constant heavy friction on the journals and frequent heated necks had caused the bearings to give way. In these experiments it appeared from page 606 that each belt was tightened up by adjusting screws to the particular tension which its maker thought best for 
it to work at. The ropes however were not touched; they were simply applied, and, whether thoy were applied rightly or wrongly, the tension gear was not used with them. What could be done in the driving of a large mill, if it were necessary to have an adjustment for the belts in every storey? With rope driving the requisite tension was obtained without adjustment; and in these particular experiments the ropes seemed to have been put on sufficiontly tight to do without any use at all of the tension gear.

The rope speed used during these trials seemed to him to be what was agreed upon by the committee as producing the best results for all diametors of ropes. Speeds of from 4,750 to 5,000 feet per minute were generally considered to produce the best results with ropes; and although Mr. Platt had referred to 6,000 feet per minute as having been tried some years ago (page 631), there were fow engineers now, he believed, who would think of going beyond 5,000 feet per minute. In connection with rope-driving in Lancashire the sizes of the ropes used were being diminished, and a greater number of ropes used, in preference to a smaller number of larger ropes. For so small a power as only 160 H.P. the ropes of $1 \frac{3}{4}$ inches diameter used in these experiments seemed to him to be rather too large; the ordinary Lancashire practice at the present time would be to use $1 \frac{1}{2}$ inch ropes for such a power. If time had permitted in the experiments, varying speeds and varying width of belts and varying number of ropes, and a number of other variations, might have been usefully tried.

The mode of determining the slip in the Lille experiments had not been stated in the Report. The thanks of mechanical engineers were due, he was sure, to their French brethren for their trouble in this matter. While all would be sorry that the experiments had not been extended further, it must be borne in mind that the expense of extending them would have been so great. Personally he desired to thank Professor Capper for the careful way in which he had placed this subject before the Institution.

Mr. Deditr Halpin thought it was a great pity that these experiments had not been so carried out as to bring to light what 
(Mr. Druitt Halpin.)

was wanted to be known, instead of what was not wanted. It need not in his opinion have necessarily cost $£ 6,000$ (page 601) to determine the friction and the absolute power absorbed by the ropes and belts, which was what engineers wanted to know. Starting at one end with indicator diagrams taken from the engine, these seemed to have been made use of without any account being taken of what the friction of the engine was. The driving was then done through the ropes and belts; and at the other end an electrical measurement was obtained, for whatever it might be worth. This final standard indeed seemed to him to be altogether on so untrustworthy a scale that he thought it could not be relied on. The indicators could be calibrated, as had been done, so as to know what was being done at the engine; but what was being done at the other end was in his opinion a matter of great doubt. If it had merely been intended to find what was the power absorbed by the ropes and belts, he thought it might have been done at a reasonable expense in the way hinted at by Mr. Longridge (page 634). If the driving pulley or fly-wheel had simply been made perfectly loose on the driving shaft, and the driven pulley also loose on the driven shaft; and if on the driven shaft had been put any work or resistance whatsoever-a centrifugal pump or a dynamo or anything else--to take up the power, whatever the amount of the power might happen to be; and if also a spider or drag-link had been fixed on each of the two pulleys, and connected with the pulleys by dynamometer springs:-then autographic diagrams could have been obtained, recording exactly what power was being put into the driving pulley, apart from what was being lost in engine friction, and also recording exactly what power was being given out by the driven pulley for performing the work. The difference between the two amounts of power thus recorded would be the power absorbed in transmission by the ropes or belts. In that way the data wanted would have been directly arrived at; and he thought the expense of making the requisite apparatus of the kind he had indicated would not have been anything considerable. Apart from the dynamometer springs, the whole of the rest of the gear was common everyday work; and the ordinary pulleys could have been used, without having necessarily to be charged to the job. 
Mr. W. Worby Bratmont thought that perhaps the criticisms already offered in the discussion as far as it had gone might suggest to Professor Capper the desirability of reviewing the figures he had given, and perhaps of adding to the value of his paper by giving some further results of the experiments. He noticed that all the belts and ropes used in the Lille experiments were presumably new, having been specially ordered (page 600) for these trials. It seemed to him a pity that some belts and ropes had not been tried which were not new, particularly belts; because it was well known that there was a great deal of difference between the losses in belt driving with old and with new belts; the grip of the pulleys by old belts was much higher for a given tension, and the journal friction correspondingly less for the same driving pull. His own observations had shown that the losses attendant upon the use of tight belts and bright pulleys were generally much under-rated. Moreover, although the tension upon the ropes and belts was given in Table 13, it was not stated how that tension was ascertained; it was only mentioned (page 606) that during the experiments with the belts the tension was regulated by the makers of the several belts, until they got whatever they considered to be the best for their own particular belts under the particular load they were working at, which was practically about the $\operatorname{sam} \theta$ in all the trials. Considering that there had been those facilities for varying the belt tensions, he thought it might naturally be expected that the results of all the experiments wonld come out pretty much the same. There would be a similar amount of bearing friction; and the losses due to bending and unbending of the belts, and to adhesion of the ropes in the grooves, would leave the amount of work to be done in each case very much the same. Hence in percentage the losses could in fact vary but little. Of the surface of the belt pulleys no mention had been made, as to whether it was highly polished or only rough turned; but its condition made a great deal of difference. The machinery at disposal for these trials he thought would rather have warranted some experiments at no great extra cost, which would have added to present knowledge, more particularly as to the amount of power absorbed or lost in these two methods of driving. 
(Mr. W. Worby Beaumont.)

The Report had certainly not given much now information; and perhaps Professor Capper might be able to add thereto from his own observations.

Mr. E. Tremlett Carter suggested driving the rope or belt gear, not by a steam engine, but by two equal dynamos, as in Dr. Hopkinson's method of testing dynamos, driving one as a dynamo and the other as a motor, somewhat on the plan mentioned by Professor Capper in page 622. With the two directly coupled, their combined mechanical effieiency could be ascertained; and from their combined efficiency it could be ascertained what would be the efficiency of each separately. On then separating the two dynamos, and making one drive the other through the rope or belt gear, from the new efficiency would be ascertained the difference which would be due to the intervention of the ropes or belt. On now taking off the ropes or belt and driving the dynamos with only the pulleys on, making the one drive the other electrically as a motor, the amount of extra bearing friction which was due to the weight of the pulleys would be ascertained. In this way three efficiencies would be obtained: firstly, the efficiency of the dynamo and motor by themselves; secondly, their efficiency when geared together by the ropes or belt; and thirdly, their efficiency when they were loaded only with the rope or belt pulleys. From those three efficiencies, and from the known electrical power supplied to the motor, might be deduced the loss of power due to the flexible connecting link, and the loss due to the friction of the pulley bearings. From his own calculations and experience he had found that the limit which determined the choice between belts and ropes was about 100 H.P.; below this power it was better to use belts, and above it ropes were preferable, as a rule. An instance of the difference had been met with in the early days of electric lighting, which happily was not met with now, where it had been necessary to develop a considerable amount of power from a dynamo running at a considerable speed. It had then been requisite to have a pulley of small diameter on the dynamo; and as ropes were injured by having to pass round such small pulleys, it had been preferable to use a thin belt. 
Mr. R. E. B. Crompton considered Mr. Carter had pointed out what was undoubtedly a very accurate way of carrying out the test in a practical manner; and it ought to have been so carried out long ago. To call that method Dr. Hopkinson's however was a mistake that was often made. Dr. Hopkinson's method consisted in obtaining the efficiency of two dynamos by driving them coupled together in such a manner that the power wasted in the two had only to be supplied by mechanical means; and the power was measured also by mechanical means by a brake. It was a method which had been a great advance on anjthing that had ever been carried out before; but it was not by any means perfect, and it had now been superseded by a method, devised almost simultaneously by three personsLord Rayleigh, Mr. Swinburne, and himself-of supplying by electricity the balance of power required to drive the two dynamos, and consequently making all the measurements by electrical means. In spite of the doubt implied in a previous speaker's remarks (page 640), electrical measurements of power might be now taken within such a percentage of accuracy that no mechanical measurements of power could be compared with them; and these electrical measurements gave such facilities that, if a series of experiments were carried out in the way proposed by Mr. Carter (page 642), data could be obtained which would be of the greatest value. Experiments and measurements of that kind were now carried out daily in many electrical engineering workshops. In carrying out the above method of testing, it was frequently the case that the dynamos could not be coupled end to end, and that it was necessary to couple them mechanically by ropes or belts, so that the friction due to side pressure on the bearings came into play; and although no careful experiments had yet been carried out, he believed it was well known to most makers of dynamos and motors that, where they had to use these means of driving, either by belts or ropes, which involved side pressure on the bearings, the power thus lost amounted to not less than from 7 to 9 per cent. This was more than double the 3 to 4 per cent. mentioned in page 629 as the total loss in well-designed belt gearing. In looking through the Report he was indeed much disappointed to find that the question of the actual 
(Mr. I. E. B. Cromputon.)

efficiency of the trunsmission was nowhere entertained. With the exception of the $68 \frac{1}{2}$ per cent. given by Professor Capper (page 623) as the combined efficiency of the whole system, he had really been unable to find anything at all about the efliciency, which was a most important and interesting feature for all ongineers. A good deal had been said about slip, and about the power of certain belts to resist tension; but he could not find any attempt to analyse the total loss due to the transmission, that is, the total loss between the indicator diagrams and the measured electrical horse-power. While he agreed with Mr. Halpin (page 640) that the indicated horse-power had probably been obtained fairly correctly from the indicator diagrams, he also thought it was clear that the electrical horse-power had been ascertained fairly correctly, so that the above combined efficiency of $68 \frac{1}{2}$ per cent. was probably nearly correct. Another mcasurement which would have been interesting, and might have been obtained, would have been that of the dynamo efficiency. The Alsatian Company, who had furnished the 200-E.P. dynamo (page 601), had certainly not constructed a dynamo of that size which could lose so much as 10 per cent. in heating up its coils, for power so wasted would soon burn them up. But even if so low an efficiency as 90 per cent. for the dynamo were adopted, and 85 per cent. for the ratio of the brake horse-power to the indicated horse-power of the fine engine used, the conclusion was inevitable that the loss in the belt as well as the rope transmission was 10 per cent. or thereabouts. Thus, indicated horse-power 100, brake horse-power 85, at pulley of dynamo after rope losses 76 , and at terminals after 10 per cent. dynamo loss $68 \frac{1}{2}$. These figures, which he had worked out from the Report, he thought were fairly correct; and they agreed fairly well with the experience of most of the electrical engineers who had been transmitting large amounts of power by means of belt and rope driving for many years past. But to electrical engineers indeed the transmission of power by rope and belt driving possessed a different kind of interest. As regarded their generating plant the day for ropes and belts had gone by, since the advent of high-speed engines had enabled dynamos to be driven direct; and they most of them thonght that a few years hence would see all machinery 
driven direct by electricity, and that belting and shafting would become curiosities of the past. Hence electrical engineers were not now so interested as formerly in the efficiency of mechanical transmission of this kind. A few days ago he had been in Cornwall, the land of flat rods and fend-off bobs, as they were called; and with the efficiency of that mode of transmission the people there seemed well content. Having worked out a few of their efficiencies for his own benefit, he had found that a very small percentage of the indicated power of the engines was being really utilized by the pumps at a distance in some cases of only 100 and even only 50 yards from the engines. As therefore he looked upon Cornwall and similar mining districts as offering a splendid field for the introduction of better modes of transmitting power, so he thought electrical engineers would a few years hence look upon all modes of rope and belt transmission as presenting an equally happy opportunity for the substitution of that silent, steady, and infinitely flexible connecting-rod which was called electricity.

Mr. William Geipen thought the method suggested by Mr. Carter (page 642) for measuring the efficiency of the rope or belt transmission would not give its efficiency at full load, that is at full tension, which he believed had been the object of these experiments. Steadiness of rope driving had been referred to by Mr. Platt (page 631) as due to high speed; and his own experience was that the steadiness did not depend on the speed alone, but also on the length of the drive. In some cases he had had to shorten the drive in order to cure the swaying and riding of the ropes. The difficulty mentioned by Mr. Platt (page 631) of getting governors to run steadily when driven by belts, instead of being direct driven, was one which he had not himself experienced. A direct driven governor he admitted was safer and more certain in some respects; but it often produced considerable extra expense in an engine, and it also rendered the engine much more diffcult to adjust to its right speed. The jumping of the laced joint over the pulleys he supposed was what constituted Mr. Platt's objection to driving a governor by a belt; but with a properly laced joint he thought there should be little 
(Mr. William Geipel.)

variation in the speed; and that little, it appeared to him, might often be an advantage in governing, for it might give the governor just the slight impetus or shake which would enable it to adjust itself to the new conditions of work.

In driving by belts in these experiments he thought it was somewhat important to know what was the amount of camber or convexity in the rim of the belt drums. If there was too much camber it would conduce to extra slip, owing to the difference in speed between the centre of the rim and its two edges. In the examples given by Mr. Longridge of short driving with ropes (page 636) he noticed that the greatest difference between the diameters of the two pulleys did not exceed $2 \cdot 3$ to $I$; and he should like to know whether there had been any experience of short driving with ropes where the ratio was as much as 6 to 1 , because in many industries one of the great reasons now for using belts or ropes was to adapt a slow-running motor to a quick-running machine. For the high speed of 6,000 feet per minute, mentioned by Mr. Platt for rope driving (page 631), he should be glad to know what sort of fly-wheels and pulleys had been used, because he believed this was considered to be the ultimate safe speed at which a cast-iron pulley should run. There did not seem to be any margin then left for a temporary increase in the speed of the pulleys, such as might occur if any part of the apparatus failed: in which case the increase of speed might jeopardise the whole of the precincts.

Mr. Michaed Lonaridae replied that there were plenty of instances where the ratio of pulleys used for rope driving was 6 to 1 , but of course in all these there was a longer distance between their centres. It was a common thing in rope driving to run the main shaft of a spinning mill at 270 and even 300 revolutions per minute, and the engines from 55 to 60 . Naturally it was impossible to get a high ratio with a short drive, except by having a large number of ropes; it was only a question of the number of ropes.

Mr. E. Trenlett Carter trusted no one would be deterred from an experiment lecause of any misapprehension arising from 
Mr. Geipel's remark (page 645) as to being unable to measure the efficiency of rope or belt transmission at full load by the electrical method he had proposed. For supposing in a given arrangement on that method the efficiency could be measured only under half load, it was evident that there would then be too many ropes, and half the number should be taken off; or, if a belt was being used, a narrower belt should be substituted. If there were 100 H.P. going mechanically between two dynamos, such a size of pulleys or such a number of ropes or such a width of belt should be used as would correspond with the mechanical power passing by the ropes or belt between the two dynamos. In that way it was quite possible to measure the ropes or belt under the same conditions of sag and strain and speed as in the Lille experiments or in any factory; and he trusted it would be done. It might be doubted whether the amount of wasted power in rope or belt gear was really different at different loads; in all probability the loss of power in the gear was the same absolute amount, he thought, at all loads.

Mr. H. Sherlex-Price asked whether the fly-wheels and pulleys used in the Lille experiments had been properly balanced. If they were not completely balanced, jumping would probably have been produced to some extent, which might have affected the slip and the loss of power in transmission. He remembered many years ago in Yorkshire a mill was nearly pulled down by a large unbalanced belt-wheel running at a speed of about 4,000 feet per minute. The wheel was mounted just outside the end of the mill, and high up; and was so badly balanced that cracks developed in the end walls of the mill, and the mill became so shaky that it had to be rebuilt at that end.

Mr. William Schönherder asked whether the shape of the rim of the belt fly-wheel used in the experiments was elliptical or circular. It was referred to in page 606 of the Report as Messrs. Van den Kerkove's form; and he should be glad to know what they had found to be the best shape. 
The President said that Mr. Robert Goodbody, of Clashawaun Jute Factory, Clara, Ireland, and Mr. A. Basil Wilson, of Belfast, being unable to come to the meeting, had communicated their views in letters which would now be read.

Mr. Robert Goonbody wrote that he did not consider the Lille installation had been erected in such a manner as English experience had proved necessary. To put ropes of $1 \frac{3}{4}$ inch diameter upon a drum of only 58 inches diameter was out of the question, if durability was expeeted of the ropes; the drum should have been nearer 88 inches diameter. The ropes he also expected had been too large for the grooves; his own experience had proved that ropes should run in their grooves almost touching the bottom. He had himself ropes of $1 \frac{1}{2}$ inch diameter running fifteen years without being taken off, working in grooves originally made for $1 \frac{3}{4}$ inch ropes. Also similar ropes running 4,000 feet per minute, giving off 40 to 43 indicated horse-power constantly for 56 hours weekly, he had found to run about eight years, without being re-spliced from the time of being put on.

Mr. A. Basil Wilson wrote that he feared the Lille experiments were by no means final. His own experience had been that ropes absorbed some 6 per cent. of the power per transmission, and belts $2 \frac{1}{2}$ per cent.; the greater loss with ropes arose from the difficulty in practice of keeping the diameters of the ropes and consequently their effective pitch-line constant. It was thus a matter seriously affecting mill-owners everywhere.

Professor CAPPER said most of the criticisms that had been offered were in such a form as not to require any answer from himself, having been simply directed towards the methods in which the Lille experiments had been carried out, for which he was not. responsible.

The shape of the Van den Kerkore rim of the belt fly-wheel (pages 646 and 647) was cylindrical in the centre for about one-fifth of the whole breadth of $18 \frac{1}{2}$ inches, Fig. 4, Plate 151 , and the outside 
tapered down conically to each edge, the radius at the edges being 0.18 inch less than in the centre; in the pulley the difference of radius at the centre and at the edges was only about half as much. So far as he knew, the rope and belt fly-wheels had not been specially balanced for the experiments (page 647), but there had been no evidence of any unequal rotation. He could not agree with the suggestion (page 645-6) that the jump of the laced joint of a belt round a governor pulley was in any way an advantage; he should certainly have thought that by this time it would have been generally found that it did not conduce to the good working of the governor.

The efficiency of $68 \frac{1}{2}$ per cent., given in page 623 as the total efficiency, was measured on volt and ampère meters, which had not been calibrated. He had therefore been obliged to avoid going into the question of the efficiency of the various portions of the transmission, because uncalibrated meters could not be reckoned upon within a margin of 5 or 6 per cent. at least, and consequently any deductions were to that extent inaccurate. In matters of this kind of course he had been entirely dependent upon what he had been enabled to ascertain; and where there had been omissions of this sort in the conduct of the experiments, he could simply say that the information was not forthcoming. The method proposed by Mr. Carter (page 642). had been referred to as a suggestion offered by M. Neu (page 622), which had been considered impracticable owing to the extent and cost. of the apparatus it would involve.

The condition of the surface of the belt pulleys (page 641) was as they had left the tool, smooth turned, but with the tool-marks upon them; they had not been specially polished. As regarded the results of the experiments, there were not any further figures which he could add (page 641), because every figure that ho had been able to obtain was embodied in the paper; there was no information he possessed which was not contained in the paper. It was the review of previous experiments, given in pages $625 \cdots 8$, which he had referred to as not an exhaustive summary (page 630), because he had not extended it so as to include all the experiments which he knew had been carried out, but had referred only to those which he thought were of practical importance to the particular purpose of the paper. 
(Professor Capper.)

The suggestions made by Mr. Halpin (page 640) were of an excellent and practical character; and he agreed with him in wishing that dynamometers could have been used in the way he had indicated. If that could have been done, he should certainly have urged it.

For the determination of the slip (page 639) the whole period of the run had been included, and the mean speed of revolution of both the fly-wheel and the pulley had been reckoned on the total run, and the slip had been determined from the difference of the corresponding circumferential speeds. From the information given by Mr. Saxon (page 639) about the proper speeds for belts and ropes he was glad to think that the speeds employed in the experiments were about right.

The ropes and belts used in the experiments (page 637) were all new, as rightly surmised by Mr. Beaumont (page 641); and that was one of the reasons why there had been a preliminary run to commence with on the morning of the first day, in order to get them into working condition. Naturally they were not even then in the condition they would have been in after weeks and months of wear. If it had been possible to vary the kind of belt in regard to its newness or oldness, of course a good deal of additional information might have been obtained, which would have been of great value.

He desired to thank Mr. Longridge for his extremely interesting observations (pages 632-6), in which he had given so considerable an amount of information. Personally he was himself largely in accord with him in the remarks he had made about the experiments, though he appreciated to the full the courtesy with which the French ongineers had treated the Institution, and was indebted to them for the information which these experiments had furnished.

The Prissident was sure the Members would join in giving Professor Capper a hearty vote of thanks for having gone over to Lille to witness these experiments on behalf of the Institution, for having translated the Report of the Commission, and for having afterwards recorded his own observations, pointing out some of the leading results obtained. He knew that no one regretted more tlan 
the author himself that the experiments had been so obviously incomplete. The results must be taken for what they were worth; and the Members were glad to get them, because they certainly did represent, as Mr. Longridge had remarked, a particular fact upon a large scale; and perhaps still more because they represented a notable act of what might be called "scientific courtesy" on the part of their continental professional brethren. He was sorry to have received a telegram from Mi. Dubreuil, the President of the Commission, stating that he was detained in Paris by illness, and therefore not able to be present. Otherwise perhaps he might have been able to give some of the reasons which had influenced his Committee, after taking so much trouble, in stopping short of carrying the experiments to a point which would have given a great deal more information.

With regard to Professor Capper's estimate of the efficiency (page 623) as measured on the volt and ampère meters, ho gathered from page 602 that the voltmeter at least had been carefully calibrated.

Professor CAPPER explained that the torsion voltmeter, mentioned in page 602 as having beeri carefully calibrated, was the instrument by which the potential difference was measured in M. Dujardin's office, and gave readings only in arbitrary units, for which the constant had not been determined. The voltmeter from which the electrical horse-power had been estimated was at the dynamo, and was therefore at some distance from the point on the main conductors to which the torsion-voltmeter leads were attached.

The President thought under those circumstances there was certainly some ground for Mr. Halpin's strictures upon electrical measurements (page 610), so far as these particular experiments were concerned. At the same time he was confident that mechanical engineers, of whom so many had experienced, like himself, the perplexing difficulty and the harassing anxiety of calibrating indicators and dynamometers for such a use as had been suggested by Mr. Halpin (page 640), would be the last to disparage electrical 
(The President.)

measurements. For he need hardly point out that there was absolutely not the slightest difficulty in making these measurements with a degree of accuracy with which the best calibrated indicator was not to be compared. It was certainly unfortunate therefore that uncalibrated instruments should have been used, which involved the possibility of errors of 5 or 6 per cent. (page 649).

As to the absolute loss of power in transmission by ropes or belts, which it was so difficult to get at, he should indeed have been glad if some information had been forthcoming of a more positive character. It had been concluded by Mr. Crompton (page 644) that the loss must be 10 per cent. of the maximum power of the engine. Somewhat imperfect experiments of his own had not pointed to so high a proportion, but to somewhere between 5 and 10 per cent. During the few remaining years which, according to Mr. Crompton, were to be allowed by electrical engineers for rope or belt transmissions to continue in use by the benighted people in Lancashire and elsewhere, it was really important to know how much was wasted by it. As soon as they did know how much was wasted by it, he was sure they would cease to use it; because it should be remembered that, inasmuch as at full load the loss was more likely 10 per cent. than 5 per cent., it would probably rise to 15 per cent. when the engine was running at from half to threequarters load, as so often happened.

Mr. Mrohate Longridge interposed that it rarely happened in Lancashire that mill engines ran much below their full load.

The President said he had often tried to find out beforehand the amount of power that would be required in a factory or works, but had never succeeded in doing so to the extent implied by Mr. Longridge's remark. He was delighted to hear that in Lancashire they knew so exactly beforehand the power which would actually be used in a factory-as distinct, of course, from the maximum power which might possibly be sometimes required-that they could put up an engine of just the power required, and so be able always to work it at full power. Engineers who lived further 
south had not yet reached that point; and it therefore often happened that their engines ran at only between 70 and 80 per cent. of full load : 75 per cent. was good, if it could be got. Consequently the loss in transmission was increased considerably in proportion, and came to mean probably a waste of 15 per cent. of the whole coal used in the factory, for the mere pleasure of driving round those elegant lines of leather, hemp, or cotton, in regard to whose behaviour there was at present such a dearth of any definite information.

Dr. Wrumam Anderson, C.B., Past-President, wrote that he had been rather disappointed with the Report of the Lille experiments on power transmission by ropes and belts. The nature of the resistance selected had practically confined the trials to one speed, so that no data had been obtained at various velocities of ropes and belts. He particularly regretted he had been unable to attend the discussion of this subject, inasmuch as one of the last announcements he had had the pleasure of making, on retiring from the Presidency of the Institution, had been that of the welcome invitation received from Lille, and of the appointment of Professor Capper to represent the Institution at these experiments (Proceedings 1894, page 23). Other opportunities he hoped might arise in future for co-operating in similar trials.

Mr. Charles Hopkinson wrote that it was to be regretted so little could be learnt from such elaborate and expensive experiments. In order to be truly instructive, the experiments should have been arranged for more than the two variable elements, namely the material of the connecting band and its contact with the pulleys. The elements which in well arranged experimental machinery might have been known variables would include, for example, the initial tension of the bands, so as to demonstrate the effect of tension in regard to losses of work, and thereby to afford some guide to the relation between aerial friction, journal friction, and resistance to bending. The method suggested in page 622 of the paper-a motor dynamo driving a generator dynamo, directly or by band-would 
(Mr. Charles Hopkinson.)

have afforded facilities for a series of experiments, in which the loss due to variations in initial tension, in shape of contacts, in number of ropes or width of belt, in band speed, in diameter of pulleys, in band load, and in band length, could have been determined with such accuracy as would have afforded a suitable basis for checking theoretical conclusions. In a series of experiments on belt driving, in which the writer is determining the slip with varying conditions of tension in the two sides of the belt, he has thus far not recorded, when driving a sensible load, any slip so low as those in Table 13; with overloaded belts he has recorded a slip of 5 per cent. and upwards. The belts tested have been plain leather, link leather, and Reddaway "camel" belts.

M. L. Ner, of Lille, who regretted that he was unable to come to the meeting, wrote that at the time of the rope and belt trials he had urged the importance of ascertaining the degree of accuracy of the measuring apparatus. The accuracy of the electrical apparatus being easily ascertained, it remained only to determine the sensitiveness of the indicator diagrams which formed the basis of the comparative measurements. For this purpose he had asked that a series of diagrams should be taken under loads continually decreasing by a small amount, such as the successive extinction of the lamps in groups of eight or ten. It would thus bave been easy to see how soon this variation of load became perceptible in the diagram; and the degree of accuracy would thus have been known with which a diagram admitted of calculating the load on an engine. At present he thought this was but little known. Unfortunately his request had not been acted upon; and he took exception to the Lille trials as being measurement tests made without knowing beforehand the sensitiveness of the means employed. It seemed rather like a chemist wishing to make a quantitative analysis, without knowing the sensitiveness of the balance he used.

M. V. Dubreurl wrote that the Société Industrielle du Nord de la France, on the proposal of their civil engineering committee, had agreed that the experiments which were to be made on the power 
absorbed by ropes and belts should be carried out under their auspices, on condition that the tests should be conducted with every possible guarantee, and should be under the supervision not only of members of the Society, but also of any foreign engineers who might desire to take part in them. With this object the engineering committee appointed a Commission of competent engineers, who, inasmuch as the experiments would be of so distinctly general a character, decided that they could not, in the limited time they could devote to the trials, deal with all the questions of the problem to the same extent that conld be done by an individual experimenter. They were also of opinion that the number of engineers invited to attend from France, Alsace, England, and Belgium, rendered it necessary that the work should be carried out concisely and quickly. Knowing that, except at the risk of excessive fatigue and consequent errors, as much cannot be expected from a number of observers as any one by himself might be willing to do, the President of the Commission limited the programme to a field of action which would have become confused if it had been more varied. The longer the duration of trials of this kind, the more liable to variation is the performance of the mechanism, while at the same time the greater is the amount of trouble entailed upon the professional assistance of any one who, like M. Dujardin, had so obligingly offered the use of his works for the experiments. For these reasons the trials were necessarily limited. After the hemp ropes, experiments might indeed have been made with cotton ropes, square ropes on the Swiss plan, india-rubber and camel-hair belts, thong or link belts, the ropes small or large, and the belts single, double, or three-ply; and these might have been driven at speeds varying from 2,000 to 8,000 feet per minute, running horizontally, obliquely, or vertically. But all this would unfortunately have introduced confusion and inaccuracy. On the whole therefore the Commission agreed with the Société Industrielle in desiring to produce a positive record, for which they could be responsible. This record has been produced, and as a record it is as accurate as possible; and the Société Industrielle would be glad if, now that this landmark has been set up, other societies would kindly take up these experiments 
(M. V. Dubreuil.)

and complete them. The Société Industrielle wished these tests to be carried out under the practical conditions of good machinery. With this aim the Commission took as a basis the speeds and other data obtained as an average from more than 100,000 horse-power of good machinery; and the dimensions of the belt fly-wheel and the number of grooves in the rope fly-wheel were specially arranged for the power which the dynamo would require, irrespective of the power that could be given out by the engine. The aim having been to give the experiments a comprehensive character and to approximate as closely as possible to the practical conditions of rope and belt driving, in the writer's opinion the calibration of the voltmeter on the dynamo did not matter, inasmuch as the Siemens and Halske torsion voltmeter and the Wiedemann and d'Arsonval galvanometer (page 602) furnished an exact measure of the resistance, while the efficiency of the dynamo did not enter into the question. As to the accuracy of indicator diagrams, this was a point which had not been gone into, because so much depended not only on the skill of the observers and the accuracy of the instruments, but also on the variations in the mechanical efficiency of the engine at different loads. Such an investigation was seen to be of too delicate a nature; and though everyone agreed in reality with $M$. Neu, it was decided to adhere to the ordinary methods of investigation. The sole object of these remarks, which the writer has the honour to present in the name of the Société Industrielle, is to show the great interest attaching to questions of motive power. They afford him at the same time the opportunity of offering to the Institution of Mechanical Engineers, and especially to Professor Capper and to those members who have been so good as to study the Report, the thanks of the Société Industrielle, with his own, for the care, attention, and courtesy with which they have dealt with this work.

Professor CApper wrote that, in order to avoid any misapprebension, he wished to explain that the scheme of the experiments professedly left out of account the absolute determination of the power absorbed. As therefor only a relative 
determination was required, it was thought by those responsible for the arrangements that it was sufficient to determine the potential difference in arbitrary units only. If these were kept constant, it was considered that the resistance would remain constant throughout the experiments. The only definite measurement of voltage was therefore made by an uncalibrated voltmeter; and in his observations (page 623) he had given the efficiency of $68 \frac{1}{2}$ per cent., as determined by its readings, for what it was worth. 
Fig: 1. Rope Fly-wheel.

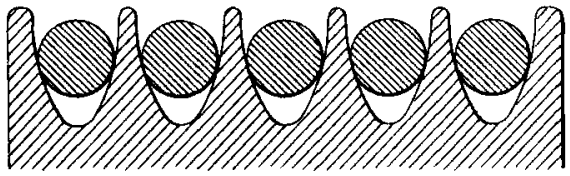

Fig: 2. Rope Pulley.

Scale $1 / 6^{\text {th }}$

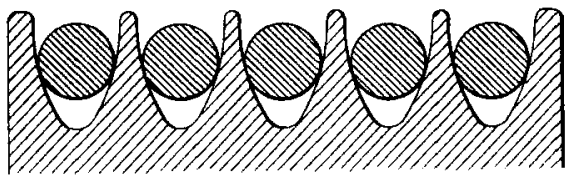

Fly-wheel. Fig: 3. Pulley.

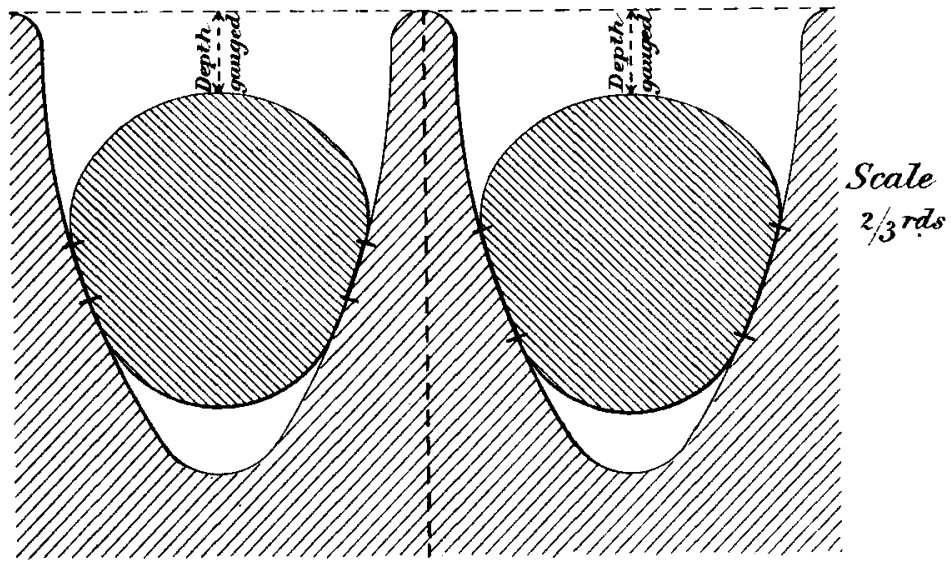

Fig: 4. Belt Fly-wheel.

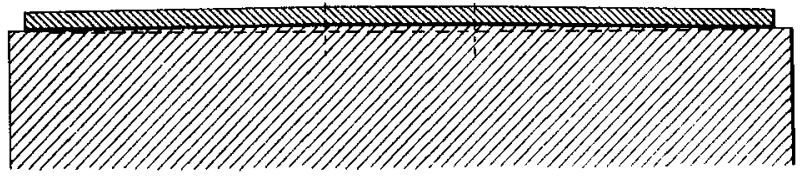

Scale

Fig: 5, Belt Pulley. 